\title{
Knowledge Integration in Science Teaching: Analysing Teachers' Knowledge Development
}

\author{
Elizabeth A. Davis \\ The University of Michigan
}

Abstract

\begin{abstract}
This paper tests the utility of a new sociocognitive frame for analysing the development of teachers' knowledge - the knowledge integration perspective (Linn, Eylon, \& Davis, in press; Linn \& Hsi, 2000). In doing so, the paper describes one prospective elementary teacher's developing knowledge and highlights its complexity. The prospective teacher demonstrates relatively well-integrated science subject matter knowledge, but she makes some problematic links to lessons and develops some instructional representations that show where she needs to distinguish between different scientific ideas. She also, however, links science concepts to appropriate real-world experiences, indicating that she has nascent useful pedagogical content knowledge. The paper discusses what teacher educators can learn about their learners from this analysis, argues for the utility of the knowledge integration perspective for conducting similar analyses, provides ideas to help science teacher educators apply the perspective easily as they teach their students, and points to areas ripe for future research.
\end{abstract}

Key Words: elementary science teachers, instructional representations, knowledge integration, pedagogical content knowledge, prospective teachers, subject matter knowledge

Strong subject matter knowledge is necessary but not sufficient for effective teaching. Teachers also need knowledge that blends subject matter and pedagogy (Ball \& Bass, 2000; Grossman, 1990). Shulman (1986) defines pedagogical content knowledge (PCK) as knowledge of the representations, analogies, and strategies useful for teaching about a particular topic - what a teacher knows to do to help students learn about an idea - as well as knowledge of students' ideas about specific topics. Prospective teachers often demonstrate little explicit pedagogical content knowledge (Lederman, Gess-Newsome, \& Latz, 1994; van Driel, Verloop, \& de Vos, 1998). Indeed, research is often grounded in the assumption that prospective teachers lack PCK (cf., Cochran \& Jones, 1998). Little is known about how teachers develop PCK, though two necessary ingredients are typically assumed to be subject matter knowledge and experience in teaching (cf., Cochran \& Jones, 1998; van Driel, Verloop, $\&$ de Vos, 1998). On the other hand, given a constructivist perspective on learning, prospective teachers must come to teacher education with a set of ideas - productive or not - that will form the beginnings of their PCK.

Following calls for empirical work on the development of PCK (Cochran \& Jones, 1998; van Driel, Verloop, \& de Vos, 1998), I analyse one prospective teacher's knowledge and its changes as she develops a unit of instruction. Rather than focus on programmatic factors that can promote the development of PCK (van Driel, De 
Jong, \& Verloop, 2002), here I instead address issues having to do with mechanism. I use a fine-grained cognitive analysis to answer two questions. First, in what ways is a prospective teacher's developing subject matter knowledge integrated with her developing PCK? Second, how do qualitative differences in her knowledge relate to the instruction - especially the instructional representations - she designs? These questions are investigated to inform a larger question: In what ways is a knowledge integration perspective useful for analysing a teacher's knowledge development?

The study is important for science teacher educators because it illustrates the utility of a new framework - the knowledge integration perspective - for describing and analysing prospective teachers' knowledge and its development. This paper focuses on the development of instructional representations, though the lens may be appropriate for analysing the development of other aspects of teachers' knowledge, as well. Because many prospective elementary teachers are learning science content at the same time as they are learning to teach science, investigating their knowledge of instructional representations necessarily includes investigating their developing subject matter knowledge, as well.

Traditionally, relatively simplistic approaches have been used to describe teachers' knowledge. For example, some studies use the number of courses a teacher has taken - for example, in a subject matter area - as a proxy for their knowledge. Others use different proxies, such as the number of years of experience in teaching. Both of these approaches are limited, in part because they assume teachers' learning involves the accretion of ideas or experiences, rather than integration (Bain, personal communication, January 23, 2002). Furthermore, though we know a fair amount about instructional strategies that can promote teacher learning (Grossman, 2003; Smith, 2000) and about what components may constitute teachers' knowledge (e.g., Ball \& Bass, 2000; Cochran \& Jones, 1998; Grossman, 1990; Magnusson, Krajcik, \& Borko, 1999; Shulman, 1986), we know far less about the cognitive mechanisms behind teachers' learning. This paper is an attempt to fill that hole. I use the case presented here to demonstrate the benefits of using the analytic lens of knowledge integration for describing and representing teachers' knowledge, including aspects that might otherwise remain hidden. That lens is described next.

\section{Theoretical Perspectives}

The knowledge integration perspective is a view of learning (Linn, 1995; Linn et al., in press) consonant with the ideas in the seminal book How People Learn (Bransford, Brown, \& Cocking, 1999). By applying the knowledge integration perspective to the types of teacher knowledge identified by Shulman (1986) and others, I consider how teachers' knowledge may become robust and integrated.

The knowledge integration perspective has been used mainly in analysing and describing students' learning of science and other subjects (e.g., Clark \& Linn, 2003; Davis, 2003; Davis, Linn, \& Clancy, 1995; Linn, Davis, \& Bell, in press; Linn \& Hsi, 2000), allowing rich descriptions and comparisons of learners' trajectories and 
identification of mechanisms or processes that support learning. In this sociocognitive perspective, learners hold a repertoire of ideas, some of which are intuitive and others that are instructed. Learners identify weaknesses in their knowledge and add new ideas to their repertoire, linking some and distinguishing between others; they also reconcile ideas that appear contradictory (Linn \& Hsi, 2000). Knowledge integration involves applying these knowledge integration processes to ideas such as scientific principles, real-world experiences, and classroom-based experiences to develop robust and usable understandings (Davis, 2003; Linn \& Eylon, 1996).

The knowledge integration perspective raises questions about the notion that a learner's poor or less useful ideas are straightforwardly replaced with better ones. Instead, ideas are assumed to change in their cueing priority (Smith, diSessa, \& Roschelle, 1994). More explanatory ideas become cued in more contexts, as learners gain knowledge and experiences and make new links. Other ideas with more limited explanatory success gradually become cued less often. For example, students may initially believe that metal is naturally cold. Although school experiences should help them adopt more scientifically correct notions (which increase in cueing priority as they are found to explain situations successfully), the old idea that metals are naturally cold will also remain in the repertoire. It will simply be applied in fewer and fewer situations.

Ma (1999), building on earlier work done by Ball (1988), claims that teachers need well-integrated knowledge. Ma identifies links that allow teachers to apply their knowledge flexibly. Lederman et al. (1994) find that as teachers progress through a teacher education program, some aspects of their knowledge becomes interconnected, though others find that ideas from university courses and programs may remain unconnected to their foundational ideas developed through their experiences in schools or with phenomena (Lortie, 1975; Putnam \& Borko, 2000; Wilson \& Berne, 1999). Because of the importance of integrated knowledge, here I characterise a prospective teacher's knowledge in terms of the knowledge integration processes of adding new ideas, making links among ideas, distinguishing between ideas, and so forth. I use the knowledge integration perspective - including the notion of cueing priority - to develop a rich characterisation of how the prospective teacher's pedagogical content knowledge and subject matter knowledge develop and are integrated. For example, ideas about how light is reflected and absorbed are integrated with each other but also with ideas about lessons, instructional representations, and assessment - in the context of light as well as in general. The study takes as a testable assumption that the knowledge integration perspective may be useful for analysing the development of teachers' knowledge.

PCK, like all knowledge, is really only useful when it is applied, so some would argue that it is not sensible to investigate PCK in prospective teachers. But this paper assumes that as prospective teachers become practising teachers, their extant PCK as displayed in their written work or interviews as well as in their classroom teaching - will be put into play as they interact with students. Understanding prospective teachers" "PCK-readiness" (Smithey, 2003) is critical.

Pedagogical content knowledge as initially defined by Shulman (1986) and later elaborated by many others (e.g., Appleton, 2003; Grossman, 1990; Magnusson et al., 
1999; McDiarmid, Ball, \& Anderson, 1989; Treagust \& Harrison, 2000) includes components such as knowledge of instructional strategies, instructional representations, classroom explanations, students' ideas, and curriculum. This study focuses on instructional representations, specifically those that link scientific principles to real-world experiences (Linn \& Songer, 1991; Ma, 1999). Prospective teachers may be able to get some traction on this aspect of PCK even without much teaching experience (Zembal-Saul, Blumenfeld, \& Krajcik, 2000). In contrast, knowledge of students' ideas and knowledge of curriculum hinge on more extensive experience as a teacher. Knowledge of instructional strategies and classroom explanations in turn require knowledge of both learners and curriculum.

Instructional representations can serve to connect scientific principles to real-world phenomena (McDiarmid et al., 1989). Linking scientific principles to real-world experiences has both promise and peril in understanding science content. On the one hand, these links occur naturally as learners move about in the physical world since our experiences with natural phenomena form the foundation of our scientific knowledge. Furthermore, helping students understand science concepts or principles through connecting those ideas to instantiations in the real-world is a successful instructional approach (e.g., Clement, 1982; Krajcik, Blumenfeld, Marx, Bass, Fredricks, \& Soloway, 1998; Linn \& Songer, 1991; Minstrell, 1989). On the other hand, learners' experiences with the real world also can foster alternative conceptions (commonly termed misconceptions). Students can understandably become confused about how what they learn in science class maps on to what they experience outside or at home (Driver, Guesne, \& Tiberghien, 1985; Linn \& Songer, 1991; White, 1993). Complicating matters further is the problem that teachers may hold the same alternative conceptions as their students do (Putnam, Heaton, Prawat, \& Remillard, 1992; Smith \& Neale, 1989). As such, emphasising teachers' links between scientific principles and real-world experiences (i.e., real world applications of those principles) is a double-edged sword: Some links will be scientifically normative and pedagogically appropriate, but others may be scientifically and pedagogically problematic.

Teacher educators, then, need to understand the possible origins of prospective teachers' instructional representations, to be better able to help them make appropriate links. This necessarily involves attending to their subject matter knowledge as well as how that subject matter is represented. In fact, teachers' subject matter knowledge and PCK can be distinguished for analytic purposes in come cases, but are too tightly interrelated in other cases to be pulled apart productively. The study reported here provides a framework for viewing this interrelated knowledge development especially as it relates to their knowledge of instructional representations.

Methods

A qualitative case study research design is adopted for this study (Merriam, 1988; Stake, 2000; Wolcott, 1994). The purpose of the case study is to better understand 
one prospective teacher's knowledge integration, and to use that analysis to consider implications for teacher education. The case study is not intended to build general theory about the learning of prospective teachers, but rather to provide fodder for other science teacher educators to use as they reflect on their learners and develop their own teacher education practice (Anderson, Smith, \& Peasley, 2000). The study tests the usefulness of the application of the lens for gaining insight into prospective teachers' learning, but does not attempt to provide a general description of all prospective teachers' knowledge integration processes.

\section{Study Context and Participants}

The study took place during the third semester of a relatively small undergraduate teacher preparation program in the United States. The four semester program emphasises inquiry-oriented teaching consonant with recommendations in teacher education reform calls (e.g., Interstate New Teacher Assessment and Support Consortium [INTASC], 1992; National Board for Professional Teaching Standards [NBPTS], 1989; National Council for Accreditation of Teacher Education [NCATE], 1987) and subject-matter standards documents (e.g., American Association for the Advancement of Science [AAAS], 1993; National Council for the Social Studies [NCSS], 1994; National Council of Teachers of Mathematics [NCTM], 1991; National Research Council [NRC], 1996) in the United States. Each semester prior to student teaching, prospective teachers in the program spend six hours/week in field (i.e., practicum) classrooms and are typically placed in the field classrooms in pairs.

My elementary science methods course provided the specific context for the study. As part of the course requirements, the prospective teachers developed a unit plan for teaching one science topic. For the unit plan, which was completed in three phases, prospective teachers wrote a rationale, described the subject matter knowledge a teacher needed to teach it effectively, developed an instructional representation they would use with children, created a calendar for the four to six weeks of instruction it covered, and fully developed five days worth of instruction plus at least one day of assessment. They taught two of these lessons in their field classrooms. (See Appendix A for the unit plan assignment.) Prospective teachers typically worked with their practicum partner on this assignment.

All but 1 of the 24 undergraduate prospective teachers in the elementary science methods course were 4th or 5th year seniors and most planned to student teach the following semester. Approximately half of the prospective teachers agreed to participate in this research project. Of those, 4 were chosen as interviewees using a purposive sampling strategy (Merriam, 1988). Interviewees were chosen to represent a range of subject area concentrations for their units. The study reported in this paper focuses mainly on a single participant, identified by the pseudonym "Val." Val was placed in a fourth grade classroom, and with a partner developed a unit plan on the topic of light. They selected this topic because of its congruence with 
their cooperating teacher's plans for the semester; neither Val nor her partner had a particular interest in light.

Val was selected as the primary focus because I determined that her case could be most instructive (Merriam, 1988; Stake, 2000). Her case allows the most explicit demonstration of patterns also seen in the analysis of the other three cases. Her concentration in the School of Education was science, which means she took at least 36 credit hours of science courses (i.e., roughly 12 college courses total, across 4-5 years), significantly more than her peers with other concentrations. Her confidence in science was important since investigating prospective teachers' subject matter knowledge can cause them to feel as though they are being tested (cf., Holt-Reynolds, 1999; Jones, Carter, \& Rua, 1999; Kennedy, 1998; Smith \& Neale, 1989). Although she had more confidence in science than many of her peers, she was nonetheless concerned about students' engagement in and learning from her science teaching. Like most of her classmates, Val was female. Unlike most of her peers, Val was not Caucasian. ${ }^{1}$ In sum, Val is similar to her peers in some ways and different in others. In the treatment below I note where generalisation is and is not appropriate based on parallel analysis of the other case study participants. In addition, I briefly describe excerpts from two other prospective teachers' cases to further illustrate and substantiate my points.

\section{Role of the Researchers and Data Sources}

In addition to teaching the science methods course, I designed and conducted the interviews. I ensured that the interviews did not take advantage of the power differential inherent between teachers and their students; for example, I clarified that participation was voluntary and would not affect prospective teachers' grades. A graduate student familiar with the research contributed to the interview design and data analyses.

Because using multiple complementary methods is most effective for assessing PCK (Baxter \& Lederman, 1999), because of my interest in the integration of different kinds of knowledge, and because of my interest in change over time, this study employs a range of data-gathering approaches. Much of the case presented here builds on two important interviews - one when Val was starting substantive work on her unit plan, and one the day she completed it. These interviews were semistructured and lasted approximately 90 minutes each. Both interviews assessed Val's subject matter knowledge and pedagogical content knowledge in the topic of light. For example, in Interview $1 \mathrm{Val}$ received a set of 5 conceptually-oriented assessment questions (cf., Holt-Reynolds, 1999). Val identified the questions she would include if she had to develop a test, provided a rationale for those choices, discussed how children might answer the questions, and answered the questions herself. This allowed assessment of her subject matter knowledge and various aspects of her PCK. Two of the assessment questions from Interview 1, reproduced in Figures 1 and 2, played an important role. ${ }^{2}$ In Interview 2, to assess her pedagogical content knowledge, Val 
The power is out in your home, and you want to telephone a friend to see if the power is out in her home too! First you must find the telephone in the dark using a flashlight.

a.

Draw in the diagram as completely as you can what must happen for you to see the

telephone.

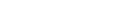

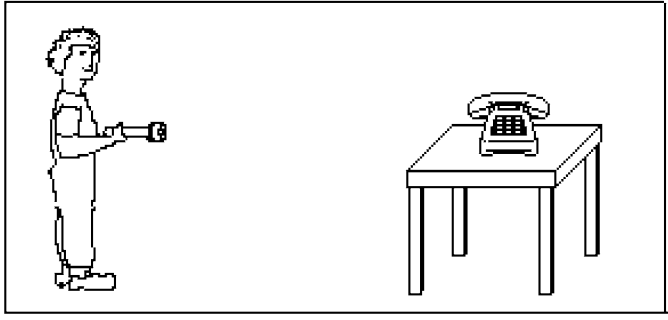

b. Explain everything that happens which allows (or does not allow) you to see the telephone:

Figure 1: The Phone Question. (The phone question is used directly from instructional materials developed by Marcia Linn and her research group; cf. http://www.clp.berkeley.edu/ or Linn and Hsi (2000).)

Joey was in a cave in New Mexico. No light was getting into the cave, and suddenly Joey's headlamp went out.

a. What would Joey need to do to be able to see again?

b. What is the main reason for your answer?

Figure 2: The Cave Question.

was asked about real-world experiences she might use to illustrate science ideas. To assess how her subject matter knowledge and PCK were integrated, Val commented on and critiqued a science activity while thinking aloud (Ericsson \& Simon, 1984). ${ }^{3}$ Though I was interested in her knowledge integration, the interview questions did not explicitly ask for particular knowledge integration processes, instead allowing them to emerge naturally from these various tasks. Other data sources include Val's written work for the course (e.g., the three phases of her unit plan, her reflective journal) plus numerous mini-interviews with Val in class and via email. These data sources are used to triangulate on assertions about Val's knowledge. ${ }^{4}$

\section{Analytic Framework and Data Analysis}

To characterise Val's knowledge integration I first identified passages of the interview transcripts having to do with two main scientific concepts within the broad topic of light: the role of light in vision and the reflection and absorption of light by black and white objects. (Scientifically, of course, these concepts are interrelated. The 
codes allowed passages to concern one or both concepts.) Within each passage, data reduction involved distilling Val's main ideas, in the form of scientific principles or propositions, real-world experiences, and classroom-based experiences. These ideas could have to do with science content, teaching, or both. (Experiences could be ones Val had or imagined.)

Then, I looked for evidence of Val's knowledge integration processes: identifying weaknesses, adding ideas, linking ideas, distinguishing between ideas, or reconciling ideas (see Table 1). I noted when Val identified weaknesses in her knowledge (or needed to do so). I identified where ideas were added across time. Ideas were coded as linked when (a) Val explicitly linked them or (b) they were juxtaposed logically. Through comparing Val's ideas to scientifically-normative ideas (i.e., ideas that are correct according to current scientifically-accepted understandings) or to accepted pedagogical ideas, I identified scientific ideas that had been or needed to be distinguished. Likewise, ideas were coded as being reconciled as compared to normative ideas. In some cases, then, coding for evidence of knowledge integration processes was relatively descriptive. In other cases, it required making judgment calls based on comparisons to scientific ideas.

Through iterative cycles of assertion generation, warrant identification, and discrepancy identification (Erickson, 1986), a case study was developed. Detailed initial case narratives (Lincoln \& Guba, 1985; Stake, 2000) described and made assertions about Val's knowledge and knowledge integration with regard to the two scientific areas. Each initial case narrative was then reviewed and edited by the graduate student involved in the project, based on the full transcripts of the interviews and Val's written coursework, to identify confirming and disconfirming evidence. This triangulation process plus regular meetings of the two researchers in which emerging findings were reviewed contribute to the credibility (i.e., internal validity) of the assertions in the cases (Lincoln \& Guba, 1985; Merriam, 1988). In addition, comparisons were made to the cases of the other prospective teachers, which were developed in parallel.

\section{Results}

To understand the results, a brief discussion of the two main scientific topics may be in order. The first theme has to do with the role of light in vision. For us to see an object light must hit the object and be reflected off of that object and back to and into our eyes. Then an image is produced at the back of the eye, to be interpreted by the brain. The second theme has to do with how black and white objects absorb and reflect light differently. Dark colors absorb more light than lighter colors, while lighter colors reflect more light than darker colors. Absorbed light is converted to heat energy. In low-light situations (e.g., at night), white objects are more visible than black objects, because they reflect more light. In high-light situations (e.g., during the day), dark colored objects get warmer than do lighter colored objects - they 
Table 1

Examples of Knowledge Integration Processes.

Knowledge Examples
integration process

Identifying

weaknesses

Adding ideas

Linking ideas

Distinguishing ideas (i.e., making distinctions)
Recognising that a phenomenon such as that a lens makes an image appear upside-down is unexplained

Adding a scientifically-normative (i.e., correct) principle that absorbed light is converted to heat energy

Adding a scientifically non-normative (i.e., incorrect) principle that ambient light 'lights up' an object even if it is not reflecting off that object

Adding a lesson scenario about darkening the classroom effectively

Linking scientifically-normative principle that light needs to be reflected off an object for us to see it to real-world experience in haunted house (i.e., applying a scientific principle to real-world experience)

Linking real-world experience in darkened closet to realworld experience in haunted house

Linking real-world experience in haunted house to lesson on light sources

Distinguishing between the scientifically-normative principles light reflecting off an object makes an object more visible and light being absorbed by an object makes the object warmer

Distinguishing between low-light and high-light situations (e.g., nighttime versus daytime)

Distinguishing between lesson goals of learning about primary colors and learning about energy conversion

Distinguishing between light and heat

Reconciling ideas

Reconciling the (incompatible) scientific principles that black objects absorb all light (non-normative) and light needs to be reflected off an object for us to see it (normative)

absorb more light which is converted to heat energy, causing the temperature to go up. Appendix B illustrates these ideas with examples. 
The results of the interviews are organised around these two topical themes and around Val's knowledge integration with regard to the themes. The knowledge integration processes in Table 1 are used to describe Val's knowledge integration. The results demonstrate how Val's developing subject matter knowledge is related to her developing pedagogical content knowledge. The results focus on how Val links scientific principles, real world experiences, and lessons to develop instructional representations or potential instructional representations. ${ }^{5}$

To preview the findings, Val makes numerous connections among principles, realworld experiences, and lessons. Some of these yield productive instructional representations, while others fall short. At times, then, Val's knowledge is both wellintegrated and effective, whereas at other times, she needs to either connect ideas or distinguish between them. After presenting a detailed analysis of Val's knowledge integration around the two main science topics, I turn to a much briefer discussion of the two other cases, to illustrate how generalisable this kind of analysis can be.

\section{Knowledge Integration around the Role of Light in Vision and the Physics and Biology of Vision}

Even at the time of Interview 1, Val shows a fairly strong and integrated understanding of the role of light in vision. When asked about the phone question, Val says:

The light has to somehow reflect off the telephone, either from the wall or from directly from the flashlight, and then those rays have to travel to his eye ... because in order to see the light, rays need to be able to go to your eye so you would be able to see something, so if there is no light at all ... I don't think you can see without light ....6

Her understanding here is excellent - she knows that the light that hits the phone could be direct light (from the flashlight) or indirect light (from the flashlight but then reflected off the walls or other objects) ${ }^{7}$, she implies that the light has to hit the phone, and she knows the light must then reflect back to the eyes. She concludes, "Light has to go to your eye."

When Val is asked about the cave question, she spontaneously brings up the idea of being able to see in a darkened bedroom, even though the lights are turned off. She then is asked what the difference is between being in a cave (where one could not see) and being able to see in your room, even if the lights are off. Val says:

In your room there are other lights around, like the neighbor's porch light, the street lights that are near your room, there are other lights in the house, and in a cave there is - I've never really been in a cave so I don't ... like if you were in a closet and you shut the light off and there's no other lights around, you can't see. Like you're in a haunted house or something - sometimes you just cannot see anything, even if your eyes do adjust, so that would be the difference. But I guess I would say that it would need you to turn on some sort of light, or find something - I don't know. Find something light, like some sort of light, I guess. ... I would hope after the lesson they would be able to understand different sources of light. 
Here, Val begins by articulating a link to a real-world experience - being able to see in a darkened room. Then in the passage quoted above, she starts with another realworld experience (in which there are lights on in the neighborhood and elsewhere in the house), giving examples of ambient light. She then tries to link this to the "target" experience of being in a cave. She notes, however, that she has not had this experience - she appears to want to make a link but is unable to do so. She links instead to experiences with which she is familiar - that of being in a darkened (and completely closed) closet, and then, a moment later, a haunted house. In both of these instances, she notes that "you just cannot see anything, even if your eyes do adjust." All of these links indicate that Val does have a fairly well-integrated understanding of the role of light in vision - she seems to understand that without light, we cannot see.

Note, however, Val's final phrase: "I would hope after the lesson they would be able to understand different sources of light." For her unit, Val developed a lesson on light sources, and appears to link the ideas in this passage - which focus on the role of light in vision, not on light sources - to the lesson she has developed, on light sources. Here Val makes a link, but it is a link to a lesson easily at hand rather than one related closely to the complex concepts she had been discussing. She may have a rich understanding of the science but not have a repertoire of ideas about teaching the particular topic from which to draw an example. Alternatively, she may not recognise the complexities of the ideas here, and may simply see her examples as instances of needing a light source to see, without considering the physical mechanisms at play. See Table 2 for a depiction of these links, which overall represent fairly wellintegrated knowledge, especially for a prospective teacher.

In Interview 2, Val gives similarly high-quality responses to questions about the role of light in vision. She also makes several unprompted and prompted links to real-world experiences. The interviewer asked her to come up with examples of places where these ideas are seen in "real life", and then for ways she might help kids understand these ideas. She generates several. For example, she links to her own experience as a child, when her siblings would try to scare her by locking her in an interior basement room with no windows or lights. Val notes that there is "absolutely no light" in this situation, and that one cannot see when there is no light (a link to a principle). Val also links to several examples of seeing white versus black objects in low-light situations, such as wearing lighter-colored clothes when going out for a walk or run at night. Her understanding is well-integrated and scientifically normative.

Unlike her understanding of the role of light in vision, though, Val's understanding of the physics and biology of the eye was limited - poorly integrated and scientifically incorrect. Val and her partner developed an ingenious lesson involving a fishbowl and other accoutrements to help their students understand the eye's mechanics. In both interviews, in class, and in her written work, Val concentrates almost exclusively on the pedagogy of the lesson, as opposed to the science content. (For example, she worries about in what order to do her two activities.) Only at the very end of the second interview does Val mention the science in this lesson - which, it 
Table 2

Knowledge Integration Processes - Specifically Linked Ideas - in Response to Cave Question (Interview \#1).

\author{
Knowledge integration status Example \\ or process
}

Can see in dark room (real-world experience)
Can see in house if there is ambient light (real-
world experience)
Attempted but unsuccessful link to cave (no real-
world experience to draw on)
Cannot see in dark, closed closet (real-world expe-
rience)
Cannot see in dark haunted house (real-world ex-
perience)
Cannot see without light, even if eyes "adjust"
(scientifically normative principle)
Need a light source to be able to see (scientifically
normative principle)
Tangentially appropriate link to lesson on light
sources (lesson)

Note that Val did not make any links to scientifically non-normative principles in this example.

turned out, was problematic for Val and her partner. Val discusses at length how they were unable to find why the image appeared upside down. Val claims that books and other text materials only ever said that the "whole lens system" causes the image to be upside down. Yet Val has learned that convex lenses make images upside down, while she perceives the eye to be a concave lens (shaped "like [a mirror] at the grocery store" - a link to a real-world experience). Val's knowledge here, though, is wrong; convex lenses "bulge out" and concave lenses appear "pushed in." So though she is correct that convex lenses can make images appear upside down if the image is formed past the focal length of the lens, her mistake about which shape of lens is called "convex" (a distinction she needed to make) causes her to be unable to reconcile her conflicting ideas about the lenses and their effects to be scientifically normative. Val identifies a weakness in her knowledge and tries (unsuccessfully) to remedy it; she adds ideas from texts to her repertoire but cannot make the links or distinctions necessary to reconcile the mismatch between her ideas. The apparent reason is that she could not find, in writing, what the links or distinctions should be. She says several times that they could not find the information (i.e., add the correct 
Table 3

Foundational Ideas and Knowledge Integration Processes in Fishbowl Lesson Example (Interview \#2).

Knowledge integration Example

status or process

Identifying weaknesses Does not know why image was upside down

in ideas

Foundational ideas

Convex lens means the image will be upside down (incomplete)

Adding ideas

Various ideas added from texts

Needs to add: situations in which convex lens yields upside down image (depends on position of object with regard to focal length of lens)

Linking ideas

Eye is a concave lens (incorrect)

Eye is shaped like mirror at grocery store

Later: inappropriately links fishbowl lesson to role of light in seeing in low-light situations

Needs to link: multiple correct ideas about lenses

Later needs to link: appropriate subject matter goals with appropriate lesson

Distinguishing ideas Needs to distinguish: effects of "whole lens system" versus single lens

Needs to distinguish: convex versus concave lens/bulged out versus pushed in lens

Later needs to distinguish: subject matter goal having to do with mechanics of eye versus seeing in low-light situations

Reconciling ideas Needs to reconcile: lens shapes with effects

idea or ideas); she never mentioned the possibility of figuring out the optics behind the lens system (which would require the other knowledge integration processes). Table 3 illustrates Val's knowledge integration processes here.

Later, the interviewer asks Val whether any of the lessons she and her partner developed got at the ideas relating to the role of light in seeing in low-light situations. Val answers, "Yes. I would say that the one about the eye [gets at these ideas]." Again, Val makes an interesting link between subject matter and pedagogy. 
Val's fishbowl lesson about the eye does not necessarily help kids understand the role of light in seeing in low-light situations; rather, it would help them learn how the eye processes light. In addition to improving her subject matter knowledge, Val may need to distinguish between different subject matter goals, and then make more appropriate links between those goals and lessons that may achieve them.

\section{Knowledge Integration around Reflection and Absorption of Light}

Val has a set of scientific and unscientific ideas about how black and white objects reflect and absorb light. In Interview 1, Val discusses how black and white objects interact with light, and makes the following statements throughout the interview:

It has something to do with light.

You can't see dark things in the dark ...

The light's reflected off the white.

The light's absorbed by the black.

If someone is dressed in all black there's no light being ... all the light's being absorbed, so it's not being reflected off them so you won't be able to see it.

Val's statement that "you can't see dark things in the dark" appears to represent an idea - perhaps an older idea in her repertoire - that has lower cueing priority, and is thus used less often than more scientific ideas, but which nevertheless maintains some power. Val's lay knowledge and scientific knowledge coexist and get drawn upon at different times. The full quote is:

You can't see dark things in the dark, but ... because with the white the light it's reflected and with dark it's absorbed so you don't see it, and if someone is dressed in all black there's no light being ... all the light's being absorbed, so it's not being reflected off them so you won't be able to see it.

Here, she begins with a less explanatory idea, but then elaborates to provide more scientific explanations, plus a link to a relevant real-world experience.

Val's statements listed above, though, also imply that she perceives that black objects absorb all the light that hits them, and that white objects reflect all the light that hits them. This notion persists into and becomes more explicit in Interview 2. Val says, for example,

With the black the light is all absorbed and so ... it's like the absence of light being reflected so you see black.

Here she appears to have added the idea about "absence of light", and also seems to have crystallised the (scientifically incorrect) idea that all light is absorbed by (everyday) black objects, which was mainly implicit in Interview 1. Val also says, "With white, [the light is] all reflected." At one point she does phrase the relationship 
as non-absolute, saying, "Black objects ... absorb more light than white" (emphasis added). She needs to distinguish between the notions of "all" and "more" or "most"; scientifically, this nuance makes a difference, because if everyday black objects truly absorbed all the light, we would not be able to see them. (The adjective "everyday" is used here to emphasise the context in which Val exists, which is not a world of the idealised objects of physics class but rather a world in which a black stapler sits on the table in front of her.) The interviewer asked a question to see how Val would reconcile her ideas that, on the one hand, black objects absorb all light, yet on the other hand (as Val could state quite clearly as described above) light needs to be reflected off an object in order for us to see it. In response, Val implied that although a black object absorbs all the light that hits it, there is light around it that allows us to see it. (Children also often hold this conception; Guesne, 1985.) She makes the reconciliation, but in a way that allows her to maintain both of her original ideas. She adds a new idea (that ambient light "lights up" an object even if it is not reflecting off that object) that allows her to link her otherwise incompatible ideas. Table 4 illustrates the knowledge integration processes involved in the development of Val's subject matter knowledge of reflection and absorption of light, as described above, across time.

As noted briefly above, Val articulates several useful ways of helping children understand that black objects absorb more light than white objects do (i.e., she links this principle to several real-world experiences). These examples are not necessarily dependent on the distinction Val needs to make between "more" and "all." Val suggests that children will be familiar with experiences like going out for family walks at night, and being told to wear lighter-colored clothes. She also mentions, "another one where you would ..., like you said, darken the classroom and then try to have black objects and white objects and which do we see better and why."

Earlier in the interview, the interviewer had suggested this idea to Val as a possible way to get at the role of reflected light in vision; Val has added the idea to her repertoire, extended it by making a link to a new idea (the interviewer did not specify that one could compare the visibility of black and white objects), and makes use of it here. (In fact, Val uses a similar scenario in the instructional representation she develops in her unit plan.) She also - in a suggestion that she never explicitly distinguishes from the first two ideas, which have to do with the visibility of white and black objects - suggests an example of using a white versus a black floating raft during the summer, saying, "I don't want to go on the black raft - it would be really hot ... because the white reflects it all [all the light] and the black absorbs it."

She suggests that she might have her students think about (or do) an experiment in which a white and a black ball are left out on the grass; they would find out that the white ball would be lower in temperature than the black one. And finally Val, who has dark hair, mentions that, "the top of my head gets hotter than some blondes would, because it absorbs more light than the white, because ... it has to do with energy but I don't know exactly the right words for it."

None of these potential instructional representations is hindered by Val's lack of distinction between reflecting or absorbing all versus most of the light. Though the 
Table 4

Foundational Ideas and Knowledge Integration Processes in Reflection and Absorption of Light Example (Interviews \#1 and \#2).

\begin{tabular}{ll}
\hline $\begin{array}{l}\text { Knowledge integration status or } \\
\text { process }\end{array}$ & Example \\
\hline Foundational ideas (Interview \#1) & $\begin{array}{l}\text { Cannot see dark things in the dark } \\
\text { Light is reflected off of white } \\
\text { Light is absorbed by black }\end{array}$ \\
Cannot see dark things in dark \\
White things reflect light \\
Black things absorb light \\
Do not see absorbed light \\
All light is absorbed if dressed all in black \\
No light is reflected \\
Cannot see black objects \\
Absence of light being reflected makes one see \\
black \\
All light is absorbed by black objects [becomes \\
more consistent and explicit] \\
All light is reflected by white objects \\
Black objects absorb more light than white \\
Light around a black object lets us see it \\
Needs to distinguish: all versus more/most light \\
May need to distinguish: ideal "physics" objects \\
versus everyday, real-world objects \\
Needs to reconcile: black objects absorb all \\
light versus light must reflect off an object for \\
us to see it and se do see black objects \\
Distinguishing ideas \\
\end{tabular}

science is not quite right, the phenomena having to do with visibility (and temperature, as will be discussed below) in the everyday world can be explained appropriately.

Since Interview 1, though, Val has added (to her explicit discussion) the ideas that black objects get hotter than white objects do and that this has something to do with light. All of the examples Val links to seem to be nascent pedagogical content knowl- 
edge, in that they are examples of representations Val could use with her students to help them understand the idea of reflection and absorption of light by black and white objects. Three of these five examples have to do with energy conversion (black absorbs more light than white, and the absorbed light is converted into heat energy) rather than about which color is more visible. In other words, Val does not distinguish clearly between reflected light making an object more visible, and absorbed light making an object warmer. While both ideas are scientifically correct, they need to be distinguished in order to teach effectively about light.

Children who do not distinguish between these ideas of visibility and temperature are likely to misconstrue the role of energy conversion in temperature change (Davis, 1998), and they are less likely to successfully integrate their knowledge. Like these children, Val appears to need to add the idea of light being converted to heat energy. She knows that black absorbs more light than white, and she knows that black gets hotter than white, but she does not know the explanation, saying only, "it has to do with energy, but I don't know exactly the right words for it." She appears to recognise the phenomenon, but not know the mechanism. With regard to this idea of energy conversion, though, Val also distinguishes between two scenarios, noting that if one were to compare wearing a black shirt to a white shirt at night, "I don't think the black shirt would feel hotter." Here she makes the important distinction that the phenomena are different in low- and high-light situations. Table 5 illustrates some of these knowledge integration processes.

How will Val put her subject matter knowledge to work for her as a teacher? In Interview 2, Val was asked to comment on a cup-painting activity. Val distinguished clearly between the two purposes of the activity (learning about primary versus secondary colors, and learning about energy conversion by different colors), and said repeatedly that she would do color mixing separately from the energy conversion portion. She focused most of her attention on the energy conversion portion. For instance, Val noted a potential cause for confusion for the students: "if ... yellow and white both reflect everything, then that could lead to some confusion." Here, she wondered aloud whether the yellow and white cups would exhibit sufficiently different temperatures; she worried about providing kids with an experience that would yield murky data. When prompted to think, however, about how she would help kids understand the role that light plays in the investigation, Val did not see as problematic the distinction that kids would need to make between light and heat. She appears to think that all kids would wonder about the role of light, although students often confound the effects of light and heat (cf., Davis, 1998). Perhaps because Val did not (explicitly) distinguish between light and heat herself, she did not see the importance of helping her students make this distinction.

\section{Generalisability: Applying the Knowledge Integration Perspective to Jody and Cassandra}

I selected Val to focus on here because much of her knowledge integration was visible to me through her writing and interviews. I also analysed the work and inter- 
Table 5

Further Knowledge Integration Processes in Reflection and Absorption of Light Example (Interviews \#1 and \#2).

Knowledge integration Example

status or process

Adding ideas

Darken the classroom and see white versus black objects (lesson)

Black objects get hotter than white objects do (principle)

Needs to add: light energy is converted to heat energy (principle)

Linking ideas

Wear light-colored clothes if you're going for a family walk at night (real-world experience)

Darken the classroom and see white versus black objects (lesson)

Floating on a black versus white raft - the black raft will get warmer (real-world experience)

Black versus white ball left outside - the white ball will be cooler (lesson)

Dark hair gets warmer on a sunny day than blond hair does (real-world experience)

Distinguishing ideas Needs to distinguish: visibility versus temperature of black and white objects

Temperature change due to energy conversion is different in day versus night (high-light versus low-light situations) Two purposes of cup-painting activity (color-mixing versus energy conversion)

views of two other prospective teachers, Jody and Cassandra, to determine whether the perspective yields similar insights into their knowledge development.

Jody was developing a unit plan on plants. Early in the semester, Jody added a new idea to her repertoire: She determined, after a discussion in and after class, that she should not use instructional representations that intentionally or unintentionally personify or anthropomorphise plants. Jody links this new idea to others in several instances throughout the semester, often talking or writing quite explicitly about her decision-making process. (Though in some cases anthropomorphism is acceptable (Treagust \& Harrison, 2000), Jody is especially concerned about inadvertently promoting the development of common alternative ideas such as plants "eating" through their roots.) At one point, Jody lists a set of criteria she would use in determining an 
effective instructional representation to use, linking these criteria to aspects of her own instruction.

Cassandra, too, spoke about instructional representations she might or might not use. Cassandra was developing a unit on dinosaurs, and wanted to use the unit as an opportunity for children to experience authentic science. For example, during her first interview, Cassandra suggested that she might develop some kind of puzzle to represent how paleontologists make inferences about the fossils they are studying. By the end of the semester, though, Cassandra decided against this plan. She makes a set of links and distinctions that show how her ideas have changed. She links the idea of fossil evidence to the idea of jigsaw puzzle pieces. Then she makes two important distinctions. First, she distinguishes between the amount of evidence available in each case, saying, "really with a puzzle you have all of the pieces ...". She notes that she could have the students be "missing" some of the puzzle pieces, but then she goes on to say, "I was thinking about how when you're looking at a dinosaur you're looking at the insides and not really the outsides. When you have a puzzle you have the colors, you have a much better picture of what you're looking at, different than when you're looking at a bunch of bones ...". The distinction between the "insides" and "outsides" is an important one here; Cassandra in fact speaks about how we can only hypothesise about what colors dinosaurs might have been. Cassandra concludes, "I couldn't think of a way to truly tie the two together." Based on the rest of the conversation, her word "truly" here seems to connote the importance of scientific accuracy as well as pedagogical appropriateness.

\section{Discussion and Implications: Developing Knowledge as a Science Teacher}

These examples demonstrate the utility of the knowledge integration perspective for analysing prospective teachers' knowledge development about instructional representations. In each case, there are numerous examples of the prospective teacher engaging in the knowledge integration processes of adding ideas to her repertoire, making links between some ideas, and distinguishing between others. Some of these nuances - especially, perhaps, about distinguishing between ideas - would have been hidden had more typical approaches to measuring teachers knowledge been used. The analysis shows that Val, Jody, and Cassandra all end the semester with relatively strong and well-integrated science knowledge about the topics for which they are developing unit plans, though Jody, in particular, started the semester feeling not very confident, stating, "It's all an abyss" when asked if she felt more knowledgeable about some science topics than others. Furthermore, we saw that Val, in particular, articulates example after example of ways scientific principles can be linked to realworld experiences. Since I have mainly used Val to illustrate the findings, I focus mainly on Val in the following discussion.

Though her subject matter knowledge does have some flaws, Val has a strong understanding of most of the subject matter she is preparing to teach, especially relative to other similar prospective elementary teachers discussed in the literature 
(Cochran \& Jones, 1998). But the analysis of Val's knowledge integration provides further evidence that strong subject matter knowledge is not sufficient for designing effective instruction (Ball \& Bass, 2000; McDiarmid et al., 1989; Grossman, 1990), because some of Val's instruction is flawed even when her understanding is strong. The goal of this study, however, was not to provide further confirmation that teachers need both subject matter knowledge and pedagogical content knowledge. Rather, the goals were to illuminate how these types of knowledge are linked and may develop in prospective teachers and to test the usefulness of the knowledge integration perspective in analysing how prospective teachers' knowledge - especially of instructional representations - develops. These ideas will be explored next.

\section{Using the Knowledge Integration Perspective to Analyse Val's Ideas}

The knowledge integration perspective supported an in-depth analysis of Val's knowledge, and in particular her development of instructional representations or potential representations. For example, it highlighted that Val was readily able to link science concepts to real-world experiences. These links may help Val be more able to develop and deploy pedagogical content knowledge (in particular, knowledge of instructional representations) when she begins to interact more extensively with learners. Ma (1999) describes how teachers need to understand real-world applications of principles to design effective instruction that remains true to the subject matter, and Val seems positioned for success in this realm.

The knowledge integration perspective also made visible places where Val's subject matter knowledge and pedagogical content knowledge were less well connected. For example, Val had strong and well-integrated subject matter knowledge of the role of light in vision. But when asked to link that subject matter knowledge to particular lessons, she links to lessons on identifying light sources and a model of the eye - lessons that are only marginally related, scientifically. Val may make these links simply because she is intimately familiar with these lessons, and they are ready at hand. Or, Val may need to make better distinctions between subject matter goals for lessons and then to make more appropriate links from these goals to lessons that actually address them. Strong subject matter knowledge, thus, does not necessarily yield effective pedagogical content knowledge (Ball \& Bass, 2000; Grossman, 1990) - even when coupled with multiple links to real-world experiences.

Using the analytic frame also makes visible that some weaknesses in Val's subject matter knowledge appear more important, from a pedagogical standpoint, than others. Consider two cases in which Val needed to distinguish between scientific ideas. First, when Val discussed how black and white objects absorbed and reflected light, she did not distinguish between absorbing (or reflecting) all versus most of the light. But she still makes useful links to real-world experiences that she would use as representations to help her students learn about how light is reflected and absorbed. The representations themselves are appropriate even without her having made the distinction. 
But in another case, a pair of undistinguished science concepts seems likely to cause Val to represent the science in a way that will cause confusion in students rather than promote understanding. Val did not distinguish between light and heat in the representations she described for teaching about how black and white objects absorb and reflect light. She also did not see the distinction as important to help children make; when asked about this, Val ignored the issue. The literature indicates that when teachers have the same alternative conceptions as their students, it affects how they teach (Putnam et al., 1992; Smith \& Neale, 1989). The analysis here points to specific cognitive actions Val needs to take: She must distinguish between two concepts herself before she will attend to children making (or not making) the same distinction.

Considering the changes in cueing priority among Val's ideas also supports the use of the knowledge integration perspective for analysing teachers' knowledge development. Val's shifts between lay and scientific knowledge, such as when she discusses seeing dark things in the dark, illustrate that conceptual change happens not by the replacement of some concepts or theories, taken as wholes, with other concepts or theories, nor even replacing some ideas or facets of ideas with others but rather that over time, some ideas gain power (or cueing priority) while others lose it (Smith et al., 1994). Different ideas are applied in different contexts based on when the ideas seem more and less useful. Since teachers' knowledge is so very context specific (Lortie, 1975; Merseth, 1996; Putnam \& Borko, 2000; Shulman, 1986), acknowledging that "old" ideas are not eliminated and may still be applied in particular contexts is especially important in teacher education. For prospective teachers with weaker subject matter knowledge - for whom the lay explanations may hold far greater priority than do the scientific explanations - the shifts in levels of explanation may be both more prevalent and more problematic (cf., Petish \& Davis, 2001). Attending to these shifts may help teacher educators better understand how to support the prospective teachers they teach.

The purpose of the study was to test the utility of the knowledge integration perspective on learning as an analytic frame for characterising teachers' knowledge development. As discussed above, it did indeed prove useful for such analysis, illuminating aspects of teachers' knowledge that would have remained hidden if we instead applied more gross measures of teachers' knowledge. But for even greater utility, the perspective would also help to improve science teacher educators' practice, even without undertaking a complete analysis of each of their students' knowledge integration during a course or program. Ways the perspective can provide such assistance are addressed in the following section.

\section{Implications for Science Teacher Educators}

The knowledge integration perspective implies that science teacher educators first need to identify their prospective teachers' foundational ideas about teaching and 
science, and then promote knowledge integration processes including adding, linking, distinguishing, and reconciling ideas. As a field, we know a fair amount about effective pedagogical strategies for teacher education (Grossman, 2003) and we are gaining knowledge of strategies that can promote the development of pedagogical content knowledge, in particular (Appleton, 2003; van Driel et al., 2002). But if we neglect to connect those strategies to our students' actual starting places - their prior knowledge - we risk promoting the development of inert knowledge, in the same way as do K-12 teachers who ignore their students' ideas (Bransford et al., 1999).

Learners have foundational ideas that should be built on, rather than replaced, removed, or ignored (diSessa, 1988; Linn, 1995; Smith et al., 1994). Prospective teachers have these foundational ideas about both teaching and subject matter. Prospective teachers' foundational ideas about teaching are developed through their apprenticeship of observation (Lortie, 1975). These ideas often exist quite separately from ideas they learn in schools of education (Putnam \& Borko, 2000; Wilson \& Berne, 1999), which are often added to a prospective teacher's repertoire but not linked, distinguished, or reconciled with other ideas. Prospective teachers' foundational ideas about science are often similar to children's alternative conceptions (Putnam et al., 1992; Smith \& Neale, 1989) and stem from their experiences in the world (e.g., Bruer, 1993; Clement, 1982). These ideas, too, may not be connected to other ideas.

Science teacher educators need first to work to identify these foundational ideas about teaching and science. Smith (2000), for example, recommends using narratives including autobiographies and descriptions of ideal science lessons as ways of learning about prospective teachers' foundational ideas about science teaching. Similarly, van Zee and Roberts (2001) describe using narrative and pictorial representations of positive science experiences as a way of bringing prospective teachers' prior knowledge and experiences to the fore. Tobin, Tippins, and Gallard (1994) review extensive literature describing how teachers can develop metaphors for themselves as science teachers, to give them and the researchers and teacher educators who work with them insight into their notions about teaching. With regard to teachers' foundational ideas about science, Gess-Newsome and Lederman (1993) focus on prospective teachers' notions of the structure of science content. They recommend allowing prospective teachers to use any format they wish (e.g., narratives, concept maps, etc.) to obtain insight into not just what prospective teachers' ideas are about science (and science teaching), but also how those ideas are integrated with one another.

The next step teacher educators must take is to help prospective teachers improve their knowledge through adding new ideas to the repertoire and then linking, distinguishing, and reconciling those ideas (Linn, 1995; Linn et al., in press). Teacher education, like much of the schooling of children, tends often to stop with adding ideas, relying on modes of instruction that lend themselves most to the transmission of ideas (Grossman, 2003). And indeed adding ideas - through any means - is an absolutely critical component of knowledge integration. But for knowledge integration to take place, some of those added ideas must be linked to one another, and others distinguished. Thus, as illustrated by Val's case, teacher educators need instructional strategies that help prospective teachers distinguish between instructional 
representations that are more and less useful, based on criteria such as the validity of the subject matter and the appropriateness of links between subject matter and its application. They need strategies that help prospective teachers see and make links between specific lessons and objectives. They need strategies that help prospective teachers make distinctions between the different possible objectives associated with teaching a particular science topic. And they need strategies that help prospective teachers - especially prospective elementary teachers - add appropriate scientific principles and then link those principles to other ideas in the repertoire. How can science teacher educators promote these knowledge integration processes?

Established pedagogical strategies for fostering teacher learning like discussing cases (Lundeberg, Levin, \& Harrington, 1999; Merseth, 1996), engaging in action research and teacher inquiry (Gore \& Zeichner, 1991; Hammer, 2000; Loughran \& Gunstone, 1997), and promoting reflection (Hatton \& Smith, 1995; Loughran, 2002), as well as newer approaches like lesson study (Lewis \& Tsuchida, 1998; Linn, Lewis, Tsuchida, \& Songer, 2000; Stigler \& Hiebert, 1999), can all promote important knowledge integration processes for teachers. For example, in lesson study, teachers may add new ideas to their repertoires through working with other teachers. They may make links between ideas when they consider, for example, how to use multiple representations of the same scientific concept or when they work on connecting specific activities to an overarching lesson objective. And they may distinguish between ideas when they see how a lesson plays out with students; the experience of being an extremely well-informed and involved observer may help them identify aspects of the students' responses that sound similar but, when really analysed, in fact imply different underlying ideas. Teacher educators need to be able to recognise how the strategies they use promote particular knowledge integration processes and determine whether they are helping to promote all the necessary knowledge integration processes in all the relevant areas, given their prospective teachers' foundational ideas.

One important limitation of this study is that I focused specifically on the prospective teachers' instructional representations - one particular aspect of their pedagogical content knowledge. I chose this aspect because it may lend itself to development among prospective teachers. Yet we must recognise that to be effective teachers, Val and her classmates will need to integrate many other kinds of knowledge, as well, including knowledge of children's ideas and knowledge of curriculum. Teacher educators should work to provide "conditions for learning about teaching" (Northfield, 1998, p. 699) to prepare prospective teachers to be ready to develop knowledge in these areas, even if they do not actually gain sufficient knowledge during the teacher education programs themselves. For instance, a teacher education program focused on understanding learners might help a new teacher think about her students in increasingly sophisticated ways over the next several years, even beyond what she learned during her time in the program itself (Levin, 2003). Pedagogical content knowledge, which is so integrally tied to real-time diagnosis and decision-making in the classroom, lends itself particularly well to this kind of lifelong learning. 


\section{Conclusion}

Val adds ideas to her repertoire, identifies weaknesses in her knowledge, makes links among some ideas, reconciles others that had been in conflict, and distinguishes among even others. Val does not consistently use her strong and well-integrated subject matter knowledge for teaching - even when it includes links to the realworld experiences that may develop into pedagogical content knowledge. Sometimes she links her scientific knowledge to lessons only marginally related. Other times she links to representations that do not distinguish among important science concepts. But sometimes, the representations she develops are absolutely appropriate (scientifically and pedagogically) for teaching the science in question. Prospective teachers may develop the beginnings of pedagogical content knowledge - and will need support in developing appropriate PCK that promotes normative knowledge of science subject matter among their students.

These analyses may help to further the field's understanding of teacher cognition and teacher education. The analyses highlight the utility of using the sociocognitive perspective of knowledge integration to analyse teachers' knowledge development. The knowledge integration perspective proved useful in making this analysis of Val's knowledge, as well as the knowledge of Jody and Cassandra.

These analyses have also highlighted some of the complexities of teacher education. Future research should describe knowledge integration of prospective teachers over longer periods of time (i.e., across an entire teacher education program, into their first years of teaching) and as they gain more extensive experience with students and with the actual demands of a classroom. Concomitantly, research should investigate what supports new teachers' knowledge integration, and how. For example, what aspects of a methods class, a student teacher's interactions with her cooperating teacher, or a new teacher's participation in an online community might promote the knowledge integration processes of adding, linking, and distinguishing among ideas? The study presented here makes a first step toward allowing us to address questions like these.

\section{Acknowledgments}

This research is funded by a PECASE/CAREER Award from the National Science Foundation, REC grant \#0092610, and a University of Michigan Horace Rackham Grant and Fellowship to the author. However, any opinions, findings, and conclusions or recommendations expressed in this publication are those of the author. I appreciate the interest and cooperation of the prospective teachers who made the research reported here possible. I thank Suzanne Wilson, Helen Harrington, and Bob Bain for their helpful comments on an earlier version of this paper presented at AERA 2001. I thank the members of the Teacher Education Study Group and the CASES research group at the University of Michigan for their help in thinking about these ideas, and especially Debra Petish for her work on this project. 
Notes

1. All knowledge is culturally shaped, and this might influence Val's responses. An analysis toward this end, however, yielded no evidence to suggest that Val's knowledge or knowledge integration was different, in a cultural sense, from that of her peers.

2. A child's complete answer to the "phone" question in Figure 1 would indicate that light comes from the flashlight and hits the phone, then reflect from the phone back to the person's eyes. Children often believe that (a) light only must hit the object (without accounting for the light traveling back from the object to the eyes) or (b) the eyes play an active role in producing the light that hits the object (Guesne, 1985). An appropriate answer to the "cave" question in Figure 2 would note that Joey will be unable to see without a source of light; without light reflecting off objects, one cannot see. Children often believe that once one's eyes "adjust," one would be able to see. This is reasonable since in most of our daily experiences, there is sufficient ambient light that our eyes adjust to the low light situation and we can see.

3 . The science activity involved painting the interior of paper cups different colors, filling the cups with water, and placing them in sunlight. Students measure the temperatures to determine which color heated up more or faster.

4. Since this research focuses more squarely on how Val made sense of teaching and learning challenges than in how well she could handle those challenges in the classroom, Val's classroom practice is not investigated in this study. The interviews, however, served as an intervention; in the Results, I note places where Val added or otherwise changed her ideas as a result of being interviewed.

5. By "potential instructional representation," I mean a representation that seems likely to serve as an instructional representation, but is not couched explicitly as such.

6. Val often interrupted herself and trailed off in her speaking. I have attempted to capture her discourse patterns through use of dashes (to indicate short breaks) and ellipses (to indicate trailing-off speech). Where no meaning will be lost or changed, ellipses are occasionally used to indicate where I have omitted words or phrases for clarity of presentation.

7. Val also showed evidence of a good ability to distinguish between the absence of light and the absence of direct light. In an episode that was fairly upsetting to Val, she observed another teacher telling students that there was no light under a table, on which a lamp was set. Val believed the teacher was attempting to help students understand that light was not traveling through the table - in other words, to understand the concept of opacity - but did so in a way that was scientifically incorrect. Val (correctly) noted that in fact, there is light under the table - but that the light is reflected off the walls or other objects, rather than shining directly on the area under the table.

Correspondence: Dr. Elizabeth A. Davis, 610 E. University Ave., Room 1323 School of Education Building, Ann Arbor, MI 48109-1259, USA

E-mail: betsyd@umich.edu 
American Association for the Advancement of Science (AAAS). (1993). Benchmarks for science literacy. New York: Oxford University Press.

Anderson, L. M., Smith, D. C., \& Peasley, K. (2000). Integrating learner and learning concerns: Prospective elementary science teachers' paths and progress. Teaching and Teacher Education, 16(5-6), 547-574.

Appleton, K. (2003). How do beginning primary school teachers cope with science? Toward an understanding of science teaching practice. Research in Science Education, 33, 1-25.

Ball, D. L. (1988). Knowledge and reasoning in mathematical pedagogy: Examining what prospective teachers bring to teacher education. Unpublished doctoral dissertation, Michigan State University, East Lansing, MI.

Ball, D. L., \& Bass, H. (2000). Interweaving content and pedagogy in teaching and learning to teach: Knowing and using mathematics. In J. Boaler (Ed.), Multiple perspectives on the teaching and learning of mathematics (pp. 83-104). Westport, CT: Ablex.

Baxter, J., \& Lederman, N. (1999). Assessment and measurement of pedagogical content knowledge. In J. Gess-Newsome \& N. Lederman (Eds.), Examining pedagogical content knowledge: The construct and its implications for science education (pp. 95-132). Dordrecht, The Netherlands: Kluwer Academic Publishers.

Bransford, J. D., Brown, A. L., \& Cocking, R. R. (Eds.). (1999). How people learn: Brain, mind, experience, and school. Washington, DC: National Academy Press.

Bruer, J. T. (1993). Schools for thought: A science of learning in the classroom. Cambridge, MA: MIT Press.

Clark, D., \& Linn, M. C. (2003). Designing for knowledge integration: The impact of instructional time. The Journal of the Learning Sciences, 12(4), 451-493.

Clement, J. (1982). Students' preconceptions in introductory mechanics. American Journal of Physics, 50(1), 66-71.

Cochran, K., \& Jones, L. (1998). The subject matter knowledge of preservice science teachers. In B. J. Fraser \& K. G. Tobin (Eds.), International handbook of science education (pp. 707-718). Dordrecht, The Netherlands: Kluwer Academic Publishers.

Davis, E. A. (1998). Scaffolding students' reflection for science learning. Unpublished doctoral dissertation, University of California at Berkeley, Berkeley, CA.

Davis, E. A. (2003). Prompting middle school science students for productive reflection: Generic and directed prompts. The Journal of the Learning Sciences, 12(1), 91-142.

Davis, E. A., Linn, M. C., \& Clancy, M. J. (1995). Learning to use parentheses and quotes in LISP. Computer Science Education, 6(1), 15-31.

diSessa, A. A. (1988). Knowledge in pieces. In G. Forman \& P. Pufall (Eds.), Constructivism in the computer age (pp. 49-70). Hillsdale, NJ: Erlbaum. 
Driver, R., Guesne, E., \& Tiberghien, A. (Eds.). (1985). Children's ideas in science. Philadelphia: Open University Press.

Erickson, F. (1986). Qualitative methods in research on teaching. In M. C. Wittrock (Ed.), Handbook of research on teaching (pp. 119-161). New York: Macmillan.

Ericsson, K., \& Simon, H. (1984). Protocol analysis. Cambridge, MA: The MIT Press.

Gess-Newsome, J., \& Lederman, N. (1993). Preservice biology teachers' knowledge structures as a function of professional teacher education: A year-long assessment. Science Education, 77(1), 25-45.

Gore, J., \& Zeichner, K. (1991). Action research and reflective teaching in preservice teacher education: A case study from the United States. Teaching and Teacher Education, 7(2), 119-136.

Grossman, P. (1990). The making of a teacher: Teacher knowledge and teacher education. New York: Teachers College Press.

Grossman, P. (2003, April). Pedagogy of teacher education. Paper presented at the American Educational Research Association, Chicago, IL.

Guesne, E. (1985). Light. In R. Driver, E. Guesne, \& A. Tiberghien (Eds.), Children's ideas in science (pp. 10-32). Philadelphia: Open University Press.

Hammer, D. (2000). Teacher inquiry. In J. Minstrell \& E. Van Zee (Eds.), Inquiring into inquiry learning and teaching in science (pp. 184-215). Washington, DC: American Association for the Advancement of Science.

Hatton, N., \& Smith, D. (1995). Reflection in teacher education: Towards definition and implementation. Teaching and Teacher Education, 11(1), 33-49.

Holt-Reynolds, D. (1999). Good readers, good teachers? Subject matter expertise as a challenge in learning to teach. Harvard Educational Review, 69(1), 29-50.

Interstate New Teacher Assessment and Support Consortium (INTASC). (1992). Models standards for beginning teacher licensing and development: A resource for state dialogue. Washington, DC: Council of Chief State School Officers.

Jones, G., Carter, G., \& Rua, M. J. (1999). Children's concepts: Tools for transforming science teachers' knowledge. Science Education, 83, 545-557.

Kennedy, M. M. (1998). Education reform and subject matter knowledge. Journal of Research in Science Teaching, 35(3), 249-263.

Krajcik, J. S., Blumenfeld, P. C., Marx, R. W., Bass, K., Fredricks, J., \& Soloway, E. (1998). Inquiry in project-based science classrooms. The Journal of the Learning Sciences, 7(3\&4), 313-351.

Lederman, N., Gess-Newsome, J., \& Latz, M. (1994). The nature and development of preservice science teachers' conceptions of subject matter and pedagogy. Journal of Research in Science Teaching, 31(2), 129-146.

Levin, B. (2003). Case studies of teacher development: An in-depth look at how thinking about pedagogy develops over time. Mahwah, NJ: Lawrence Erlbaum Associates.

Lewis, C., \& Tsuchida, I. (1998). A lesson is like a swiftly flowing river: Research lessons and the improvement of Japanese education. American Educator, Winter, $14-17,50-52$. 
Lincoln, Y., \& Guba, E. (1985). Naturalistic inquiry. London: Sage.

Linn, M. C. (1995). Designing computer learning environments for engineering and computer science: The scaffolded knowledge integration framework. Journal of Science Education and Technology, 4(2), 103-126.

Linn, M. C., Davis, E. A., \& Bell, P. (Eds.). (in press). Internet environments for science education. Hillsdale, NJ: Lawrence Erlbaum Associates.

Linn, M. C., \& Eylon, B.-S. (1996, July). Lifelong science learning: A longitudinal case study. Paper presented at the Cognitive Science Conference, San Diego, CA.

Linn, M. C., Eylon, B.-S., \& Davis, E. A. (in press). The knowledge integration perspective on learning. In M. C. Linn, E. A. Davis, \& P. Bell (Eds.), Internet environments for science education. Hillsdale, NJ: Lawrence Erlbaum Associates.

Linn, M. C., \& Hsi, S. (2000). Computers, teachers, and peers: Science learning partners. Hillsdale, NJ: Lawrence Erlbaum Associates.

Linn, M. C., Lewis, C., Tsuchida, I., \& Songer, N. B. (2000). Beyond fourth-grade science: Why do US and Japanese students diverge? Educational Researcher, 29(3), 4-14.

Linn, M. C., \& Songer, N. B. (1991). Teaching thermodynamics to middle school students: What are appropriate cognitive demands? Journal of Research in Science Teaching, 28, 885-918.

Lortie, D. (1975). Schoolteacher: A sociological study. Chicago: University of Chicago Press.

Loughran, J. J. (2002). Effective reflective practice: In search of meaning in learning about teaching. Journal of Teacher Education, 53(1), 33-43.

Loughran, J. J., \& Gunstone, R. (1997). Professional development in residence: Developing reflection on science teaching and learning. Journal of Education for Teaching, 23(2), 159-178.

Lundeberg, M. A., Levin, B. B., \& Harrington, H. L. (Eds.). (1999). Who learns what from cases and how? The research base for teaching and learning with cases. Mahwah, NJ: Lawrence Erlbaum.

Ma, L. (1999). Knowing and teaching elementary mathematics. Mahwah, NJ: Lawrence Erlbaum.

Magnusson, S., Krajcik, J., \& Borko, H. (1999). Nature, sources, and development of pedagogical content knowledge for science teaching. In J. Gess-Newsome \& N. Lederman (Eds.), Examining pedagogical content knowledge: The construct and its implications for science education (pp. 95-132). Dordrecht, The Netherlands: Kluwer Academic Publishers.

McDiarmid, G. W., Ball, D. L., \& Anderson, C. W. (1989). Why staying one chapter ahead doesn't really work: Subject-specific pedagogy. In M. C. Reynolds (Ed.), Knowledge base for the beginning teacher (pp. 193-205). New York: Pergamon.

Merriam, S. B. (1988). Case study research in education: A qualitative approach. San Francisco: Jossey-Bass.

Merseth, K. (1996). Cases and case methods in teacher education. In J. Sikula (Ed.), Handbook of research on teacher education (2 ${ }^{\text {nd }}$ ed., pp. 722-744). New York: Macmillan. 
Minstrell, J. A. (1989). Teaching science for understanding. In L. B. Resnick \& L. E. Klopfer (Eds.), Toward the thinking curriculum: Current cognitive research (pp. 129-149). Alexandria, VA: 1989 Yearbook, ASCD.

National Board for Professional Teaching Standards (NBPTS). (1989). Toward high and rigorous standards for the teaching profession. Detroit, MI: National Board for Professional Teaching Standards.

National Council for Accreditation of Teacher Education (NCATE). (1987). NCATE standards, procedures, and policies for the accreditation of professional education units: The accreditation of professional education units for the preparation of professional school personnel at basic and advanced levels. Washington, DC: National Council for Accreditation of Teacher Education.

National Council for the Social Studies (NCSS). (1994). Expectations of excellence: Curriculum standards for social studies. Washington, DC: National Council for the Social Studies.

National Council of Teachers of Mathematics (NCTM). (1991). Professional teaching standards for teaching mathematics. Reston, VA: National Council of Teachers of Mathematics.

National Research Council (NRC). (1996). National science education standards. Washington, DC: National Research Council.

Northfield, J. (1998). Teacher educators and the practice of science teacher education. In B. J. Fraser \& K. G. Tobin (Eds.), International handbook of science education (pp. 695-706). Dordrecht, The Netherlands: Kluwer Academic Publishers.

Petish, D. A., \& Davis, E. A. (2001, March). Subject matter knowledge and goal preferences among preservice elementary science teachers. Paper presented at the National Association of Research on Science Teaching Conference, St. Louis, MO.

Putnam, R. T., Heaton, R. M., Prawat, R. S., \& Remillard, J. (1992). Teaching mathematics for understanding: Discussing case studies of four fifth-grade teachers. The Elementary School Journal, 93(2), 213-228.

Putnam, R., \& Borko, H. (2000). What do new views of knowledge and thinking have to say about research on teacher learning? Educational Researcher, 29(1), 4-15.

Shulman, L. S. (1986). Those who understand: Knowledge growth in teaching. Educational Researcher, 15(2), 4-14.

Smith, D. (2000). Content and pedagogical content knowledge for elementary science teacher educators: Knowing our students. Journal of Science Teacher Education, 11(1), 27-46.

Smith, D. C., \& Neale, D. C. (1989). The construction of subject matter knowledge in primary science teaching. Teaching and Teacher Education, 5(1), 1-20.

Smith, J. P., diSessa, A. A., \& Roschelle, J. (1994). Misconceptions reconceived: A constructivist analysis of knowledge in transition. The Journal of the Learning Sciences, 3(2), 115-163.

Smithey, J. (2003). Two perspectives on expertise in elementary science teaching. Ann Arbor, MI: University of Michigan. 
Stake, R. E. (2000). Case studies. In N. Denzin \& Y. Lincoln (Eds.), Handbook of qualitative research (pp. 435-454). Thousand Oaks, CA: Sage.

Stigler, J., \& Hiebert, J. (1999). The teaching gap. New York: The Free Press.

Tobin, K., Tippins, D., \& Gallard, A. (1994). Research on instructional strategies for teaching science. In D. L. Gabel (Ed.), Handbook of research on science teaching and learning (pp. 45-93). New York: Macmillan.

Treagust, D., \& Harrison, A. (2000). In search of explanatory frameworks: An analysis of Richard Feynman's lecture 'Atoms in motion.' International Journal of Science Education, 22(11), 1157-1170.

van Driel, J., De Jong, O., \& Verloop, N. (2002). The development of preservice chemistry teachers' pedagogical content knowledge. Science Education, 86, 572590.

van Driel, J., Verloop, N., \& de Vos, W. (1998). Developing science teachers' pedagogical content knowledge. Journal of Research in Science Teaching, 35(6), 673-695.

van Zee, E., \& Roberts, D. (2001). Using pedagogical inquiries as a basis for learning to teach: Prospective teachers' reflections upon positive science learning experiences. Science Education, 85, 733-757.

White, B. (1993). Intermediate causal models: A missing link for science education? In R. Glaser (Ed.), Advances in instructional psychology (Vol. 4, pp. 177-252). Hillsdale, NJ: Lawrence Erlbaum Associates, Inc.

Wilson, S. M., \& Berne, J. (1999). Teacher learning and the acquisition of professional knowledge: An examination of research on contemporary professional development. In A. Iran-Nejad (Ed.), Review of research in education (pp. 173209). Washington, DC: AERA.

Wolcott, H. F. (1994). Transforming qualitative data: Description, analysis, and interpretation. Thousand Oaks, CA: Sage.

Zembal-Saul, C., Blumenfeld, P., \& Krajcik, J. (2000). Influence of guided cycles of planning, teaching, and reflection on prospective elementary teachers' science content representations. Journal of Research in Science Teaching, 37(4), 318339.

Appendix A: Abbreviated Unit Plan Assignment

(Students' version included elaborations of each of the sections of the assignment)

Your semester project will be an instructional unit for your future use in teaching elementary science. You will prepare a plan for a project to be taught over 4-6 weeks on a science topic of your choice. You should choose a topic that interests you and that will give you the opportunity to try out parts of your plan within the context of your placement.

As you plan your project, keep in mind these guidelines: 
1. The unit should be largely inquiry-oriented. You may want to include some other kinds of activities (like stories, arts, direct instruction, etc.) but the lessons you develop more fully should be inquiry-based, since that is the focus of this course.

2. The unit must be anchored and contextualised in the real-life experiences of your students.

3. The unit should approach learning from the standpoint of teaching for understanding, in the ways we've read about and discussed in class.

Phase 1: Project Proposal

Your unit should be inquiry-based and designed around a series of investigations students will carry out to answer a driving question.

Project proposals should include:

1. Cover page: Includes your name(s), course number, and date

2. The subject area in science you are working in

3. The grade level you are planning for

4. A discussion of the instructional approach(es)

5. A discussion of your driving question and sub-questions

6. The main concepts you'll address

7. A discussion of student objectives, including map on to Benchmarks

8. A discussion of investigations and activities

9. A bibliography

Phase 2: Content \& Enactment Plan

In Phase 2, you will start to think about the details of your instructional unit, identifying concepts to teach and preparing instructional activities to address those concepts.

For Phase 2, you will turn in:

1. a few paragraphs summarising what you have accomplished on your semester project and what areas you are having trouble with,

2. your current driving question,

3. a discussion of the subject matter knowledge a teacher will need,

4. identification and discussion of children's ideas and alternative conceptions in this topic,

5. a description of a "pivotal case" you'll use for addressing one alternative conception (or set of related alternative conceptions),

6. one lesson plan for one or more instructional days, and

7. a bibliography.

Phase 3: The Completed Project

For the final project, you will turn in:

1. a cover page with your name(s), date, and the unit's intended grade level(s). 
2. a statement of the driving question and a rationale for the driving question

3. a discussion of the instructional approach(es)

4. discussion of teacher subject matter knowledge

5. discussion of student objectives, including how they map on to Benchmarks

6. discussion of investigations and activities

7. a calendar

8. discussion of students' alternative conceptions and ideas

9. a pivotal case

10. daily lesson plans

11. an assessment activity plan and rubric

12. a bibliography

For almost all of Phase 3, your main work will be in refining your ideas from earlier in the semester. Each piece of the final project, with the exception of the calendar and assessment plan and rubric, will have been turned in, in some form, in at least one of the earlier phases. Use this opportunity to incorporate feedback from your instructor, changes in your own thinking, ideas you've gotten from your cooperating teacher or from actually teaching parts of the unit, etc. This is an opportunity for reflection and refinement.

Appendix B: Scientifically-Normative (i.e., Correct) Ideas about Light, with Examples

Ideas about the Role of Light in Vision

We see objects because light is reflected off of them into our eyes. (With absolutely no light, we cannot see.)

Light may come directly from a light source or indirectly after reflecting off other surfaces.

Light is transmitted into the eye to form an image, which is interpreted by the brain.

\section{Examples}

We see a book because light hits the book and is reflected off of the book into our eyes.

Direct: Light shines from a lamp on to an object. Indirect: Light from a lamp is reflected off of walls and then hits an object.

We see the book when the light that is reflected off of the book enters our eyes. An (upside-down) image of the book is formed at the back of the eye; the brain interprets the image to tell us it's a book. 
Ideas about the Reflection and Absorption of Light off Black and White Objects Dark colors absorb more light than lighter colors. (Some light is reflected.)

Lighter colors reflect more light than darker colors. (Some light is absorbed.) Absorbed light is converted to heat energy.

In low-light situations, white objects are more visible than black objects, because they reflect more light.

In high-light situations, dark colored objects get warmer than do lighter colored objects - they absorb more light which is converted to heat energy, causing the temperature to go up.

\section{Examples}

A black T-shirt absorbs more light than a white T-shirt. (We can still see the Tshirt, though, so some light is reflected.) A white T-shirt reflects more light than a black T-shirt.

When a black T-shirt absorbs light energy, the T-shirt gets warmer because the absorbed light is being converted to heat energy.

A bicyclist wearing white while riding at night is more visible than a bicyclist wearing black, because more of the light that hits the person wearing white is reflected, whereas more of the light that hits the person wearing black is absorbed (leaving less to be reflected).

A person wearing a black T-shirt on a sunny day will probably be warmer than a person wearing a white T-shirt on the same day, because more of the light that hits the black T-shirt is absorbed. That absorbed light is converted to heat energy, which makes the temperature go up. The white T-shirt, on the other hand, reflects more light, so less light is absorbed and converted to heat energy. 